\title{
Fatigue of single- and double-rivet self-piercing riveted lap joints
}

\author{
K. IYER ${ }^{1}$, S. J. HU ${ }^{1}$, F. L. BRITTMAN ${ }^{1}$, P. C. WANG ${ }^{2}$, D. B. HAYDEN ${ }^{2}$ and S. P. MARIN ${ }^{2}$ \\ ${ }^{1}$ Department of Mechanical Engineering, University of Michigan, Ann Arbor, MI, USA, ${ }^{2}$ Enterprise Systems Lab, R\&D Centre, General Motors \\ Corporation, Warren, MI, USA
}

Received in final form 7 June 2005

\begin{abstract}
The fatigue behaviour of single- and double-rivet aluminum alloy 5754-O self-piercing riveted (SPR) lap joints has been investigated experimentally and analytically. With the single rivet, the experimental program involves a set of 27 cyclic tension tests on joints with 1-, 2- or 3-mm-thick sheet coupons. In most cases (85\%), fatigue cracks are found to initiate in the gross section on the faying surface of the upper sheet. With two rivets (installed in two rows), the experimental program consists of nine cyclic tension tests, three for each of the three combinations of riveting orientation possible, on SPR joints consisting of 2-mm-thick sheet specimens. The fatigue life of double-rivet joints is found to be strongly dependent on the orientation combination of the rivets. Monotonic tests with the double-rivet joints also reveal an influence of orientation combination. In addition to experiments, values of local stress and rivet-sheet microslip in the single-rivet joints have been evaluated through three-dimensional elastic finite-element analysis. The analyses are used to interpret experimental observations of fatigue crack initiation location, life and fretting damage severity.
\end{abstract}

Keywords fatigue; gross section; lap joint; net section; self-piercing rivet.

\section{INTRODUCTION}

Despite the ductile rupture of the upper sheet into two separate pieces during the forming process, the selfpiercing riveted (SPR) lap joint has been shown to possess fatigue properties that are comparable or superior to otherwise identical spot-welded joints found in automotive assemblies. ${ }^{1,2}$ In self-piercing riveting, a tubular rivet made from a high-strength steel alloy is forced through a pair of partially overlapping sheets that are supported by a rigid circular die with an axisymmetric cavity. The diameter of the die and rivet are similar. The sheet material is typically an automotive aluminum alloy such as 5754-O or 6111-T4. SPR joints are unique owing to the manner in which they are produced, as outlined in Fig. 1, which shows the riveting/piercing procedure and a crosssectional view of a joint. The joint is cold formed with the rivet walls experiencing large amounts of compressive (shear) plastic deformation. The upper sheet is pierced through its entire thickness by the rivet, predominantly in shear, and the lower sheet is pierced only partially. Pierc-

Correspondence: K. Iyer. E-mail: kiyer@arl.army.mil ing forces cause the lower sheet to flow into the die cavity locally and conform to the cavity shape. The entire process, completed in $\sim 1 \mathrm{~s}$, involves high strain rates. In contrast standard riveted joints are produced by upsetting cylindrical pins along their axes after insertion into pre-drilled holes in the sheets.

As is the case with other types of riveted and bolted joints, the local movements at contacting surfaces, contact pressures and bulk stresses ostensibly determine the monotonic and cyclic strength of SPR joints. These parameters are related to the amount of fretting damage also. ${ }^{3}$ This paper presents an experimental and analytical investigation of the fatigue behaviour of automotive aluminum alloy 5754-O single-rivet and double-rivet SPR lap joints. For the single-rivet joints, three combinations of sheet thicknesses are considered. For the double-rivet joints, three riveting orientation combinations are considered. In addition to reporting fatigue life measurements and fretting characteristics of the single- and double-rivet joints, three-dimensional (3D) elastic finite-element analysis (FEA) of the single-rivet joints is performed to evaluate the load-induced local distributions of relative microslip, contact pressure and bulk stress. 


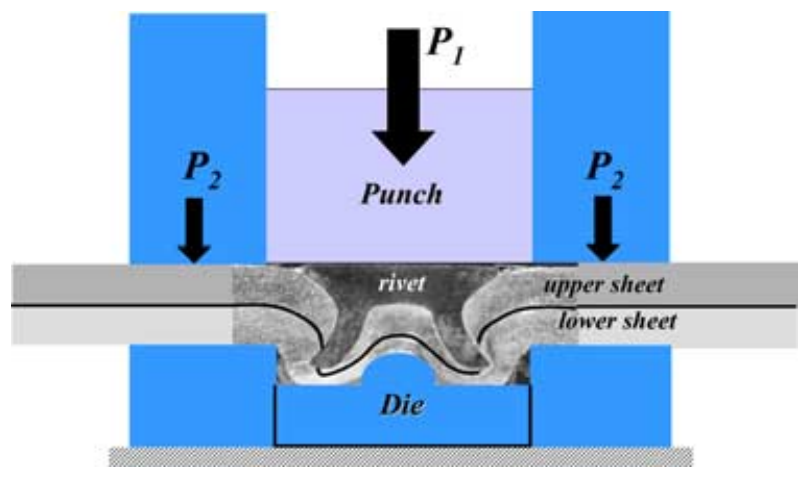

Fig. 1 Schematic showing a cross-sectional view of a self-piercing riveting (SPR) operation. A clamping force, $P_{2}=5 \mathrm{kN}$, is applied to prevent lateral sheet movements while a displacement-controlled punch forces the rivet through the sheets.

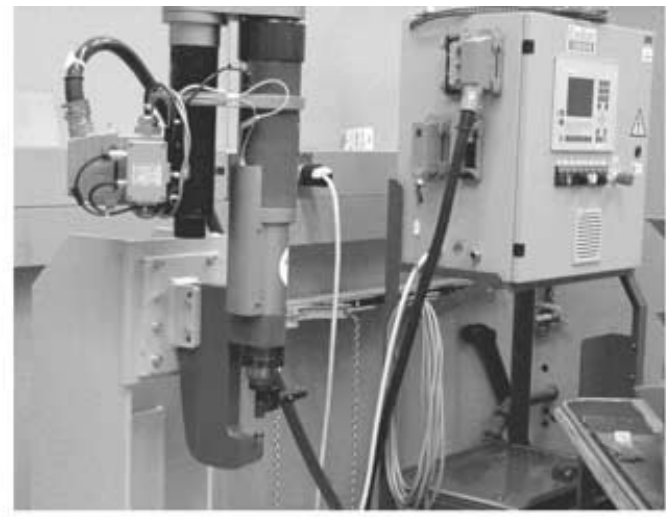

(a)

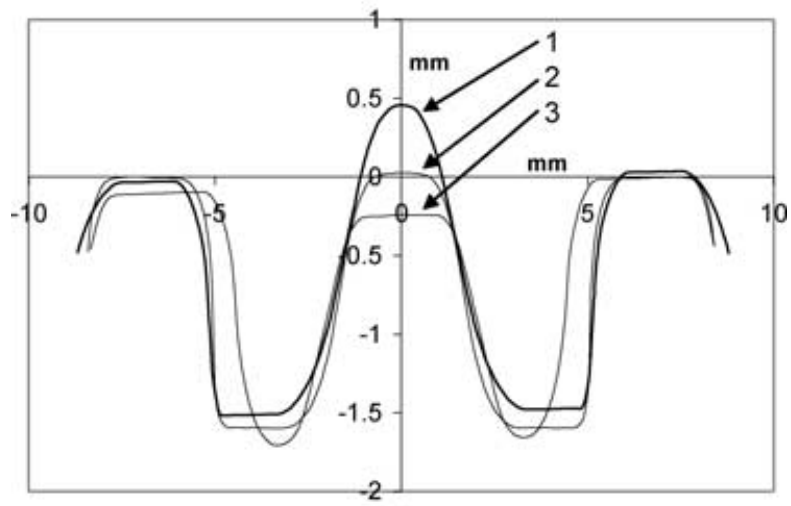

(b)

Fig. 2 (a) SPR apparatus used in the study. (b) Profiles of the three dies, labelled 1, 2 and 3, used to fabricate the SPR joints.

\section{PROCEDURES}

\section{SPR joints fabrication}

A system, shown in Fig. 2a, provided by the Emhart Fastening Teknologies (Mt Clemans, MI, USA), was used to fabricate SPR joints used in the study. The system consists of an electric motor driven setting unit and control unit with LCD display. The controller enables the specific programming of the process variables. The machine has a setting speed of $96 \mathrm{~mm} \mathrm{~s}^{-1}$ and a setting force of $80 \mathrm{kN}$. The clamping force, which holds the sheet material in place during riveting, was about $5 \mathrm{kN}$. Three types of dies, cross-sectional outlines of which are shown in Fig. 2b, were used.

\section{Fatigue tests of single- and double-rivet SPR joints}

A total of 27 cyclic tension tests, described in Tables 13 , were performed on single-rivet SPR lap joints. These joints were fabricated from 5754-O aluminum alloy sheet material and low-carbon steel rivets. Joints obtained with three combinations of sheet thickness (stack-up), i.e., $1 \mathrm{~mm}-1 \mathrm{~mm}, 2 \mathrm{~mm}-2 \mathrm{~mm}$ and $3 \mathrm{~mm}-3 \mathrm{~mm}$, were produced and tested. Each sheet in a joint was $32 \mathrm{~mm}$ wide and $132 \mathrm{~mm}$ long; the length of the overlap region was $32 \mathrm{~mm}$. The rivet dimensions (length and diameter) were selected according to current process guidelines for each gage combination and are listed in Table 1 . The die type used for each joint is also indicated. Cyclic tension tests were performed for nominal cyclic loads defined by $889 \mathrm{~N}<P_{\max }<5338 \mathrm{~N}$ and $R=0.1$, where $P_{\text {max }}$ and $R$ are the maximum load and stress ratio for the cycle, respectively.

Double-rivet joints, with the two rivets arranged in adjacent rows, were also fabricated and tested. Three types of double-rivet SPR joints are possible by altering the riveting orientation combination, shown in Fig. 3. The types $\mathrm{B}$ and $\mathrm{C}$ can be differentiated by the portion of each rivet that is most proximal to the loaded end of the joint. With type B, the applied load interacts with the heads ( $P_{1 B}$ and $P_{4 B}$ in Fig. 3$)$ of the two rivets first, whereas with type $\mathrm{C}$, the applied load encounters the lower section $\left(P_{1 C}\right.$ and $P_{4 C}$ in Fig. 3$)$ of the rivets first. A total of nine cyclic tension tests were performed on the double-rivet SPR lap joints, with each orientation combination being tested three times to ensure repeatability. To examine the influence of orientation combination on joint static strength, monotonic tests of the doublerivet joints were also performed. All double-rivet joints were fabricated from 5754-O aluminum alloy sheet material. Each sheet in a double-row joint was $130 \mathrm{~mm}$ long, $32 \mathrm{~mm}$ wide and $2 \mathrm{~mm}$ thick; the length of the overlap region was $51 \mathrm{~mm}$. The rivet length and diameter were $6.5 \mathrm{~mm}$ and $5.3 \mathrm{~mm}$, respectively, and die type 2 was used. The penetration-of-head ( $\mathrm{POH}$ ) value used was $1.5 \mathrm{~mm}$, which was determined iteratively to ensure flushness of the rivet head with the joint surface. Fatigue tests for the double-rivet specimens were performed for $P_{\max }=$ $7117 \mathrm{~N}$ and $R=0.1$.

All mechanical testing was performed under normal laboratory conditions at a frequency of $1 \mathrm{~Hz}$, on a standard 
Table 1 Single-rivet SPR lap joint fabrication parameters and measured fatigue response with $1 \mathrm{~mm}$ thick aluminum alloy 5754-O sheets

\begin{tabular}{|c|c|c|c|c|c|c|c|}
\hline S.No. & $\begin{array}{l}\text { Rivet } \\
\text { size }(\mathrm{mm})\end{array}$ & $\begin{array}{l}\text { Rivet head } \\
\text { set-down (mm) }\end{array}$ & Die & $P_{\max }(\mathrm{N})$ & $P_{\min }(\mathrm{N})$ & $N_{\mathrm{f}}$ (cycles) & Primary failure features \\
\hline 1. & $4 \times 3$ & 0.4 & 1 & 1112.00 & 111.36 & 389370 & Top sheet crack $\sim 1 \mathrm{~mm}$ above rivet head \\
\hline 2. & $4 \times 3$ & 0.4 & 1 & 1779.20 & 177.92 & 30180 & Top sheet crack $\sim 1 \mathrm{~mm}$ above rivet head + rivet pull-out \\
\hline 3. & $4 \times 3$ & 0.4 & 1 & 1779.20 & 177.92 & 24450 & Top sheet crack $\sim 1 \mathrm{~mm}$ above rivet head + rivet pull-out \\
\hline 4. & $4 \times 3$ & 0.4 & 1 & 978.56 & 97.92 & 1007280 & Top sheet crack $\sim 1 \mathrm{~mm}$ above rivet head \\
\hline 5. & $4 \times 3$ & 0.4 & 1 & 934.08 & 93.44 & 1358010 & Top sheet crack $\sim 1 \mathrm{~mm}$ above rivet head \\
\hline 6. & $4 \times 3$ & 0.4 & 1 & 889.60 & 88.96 & 1230570 & Top sheet crack $\sim 1 \mathrm{~mm}$ above rivet head \\
\hline 7. & $4 \times 3$ & 0.4 & 1 & 1556.80 & 155.84 & 38640 & Top sheet crack $\sim 1 \mathrm{~mm}$ above rivet head + rivet pull-out \\
\hline 8. & $4 \times 3$ & 0.4 & 1 & 1334.40 & 133.44 & 110130 & Top sheet crack $\sim 1 \mathrm{~mm}$ above rivet head + rivet pull-out \\
\hline 9. & $4 \times 3$ & 0.4 & 1 & 1334.40 & 133.44 & 114420 & Top sheet crack $\sim 1 \mathrm{~mm}$ above rivet head \\
\hline 10. & $4 \times 3$ & 0.4 & 1 & 1334.40 & 133.44 & 87300 & Top sheet crack $\sim 1 \mathrm{~mm}$ above rivet head \\
\hline
\end{tabular}

Table 2 Single-rivet SPR lap joint fabrication parameters and measured fatigue response with $2 \mathrm{~mm}$ thick aluminum alloy 5754-O sheets

\begin{tabular}{|c|c|c|c|c|c|c|c|}
\hline S.No. & $\begin{array}{l}\text { Rivet } \\
\text { size }(\mathrm{mm})\end{array}$ & $\begin{array}{l}\text { Rivet head } \\
\text { set-down (mm) }\end{array}$ & Die & $P_{\max }(\mathrm{N})$ & $P_{\min }(\mathrm{N})$ & $N_{\mathrm{f}}$ (cycles) & Primary failure features \\
\hline 11. & $5.5 \times 5$ & 1 & 2 & 4892.80 & 489.60 & 17609 & Top sheet crack $\sim 1 \mathrm{~mm}$ above rivet head + rivet pull-out \\
\hline 12. & $5.5 \times 5$ & 1 & 2 & 4892.80 & 489.60 & 10238 & Top sheet crack $\sim 1 \mathrm{~mm}$ above rivet head + rivet pull-out \\
\hline 13. & $5.5 \times 5$ & 1 & 2 & 4892.80 & 489.60 & 10886 & Top sheet crack $\sim 1 \mathrm{~mm}$ above rivet head + rivet pull-out \\
\hline 14. & $5.5 \times 5$ & 1 & 2 & 2891.52 & 289.28 & 236756 & Top sheet crack $\sim 0.5 \mathrm{~mm}$ above rivet head \\
\hline 15. & $5.5 \times 5$ & 1 & 2 & 3336.32 & 333.44 & 204229 & Top sheet crack $\sim 1 \mathrm{~mm}$ above rivet head \\
\hline 16. & $5.5 \times 5$ & 1 & 2 & 3336.32 & 333.44 & 159767 & Top sheet crack $\sim 0.5 \mathrm{~mm}$ above rivet head \\
\hline 17. & $5.5 \times 5$ & 1 & 2 & 3336.32 & 333.44 & 198619 & Top sheet crack $\sim 1 \mathrm{~mm}$ above rivet head \\
\hline 18. & $5.5 \times 5$ & 1 & 2 & 2001.92 & 200.32 & 4725726 & Top sheet crack $\sim 2 \mathrm{~mm}$ above rivet head \\
\hline 19. & $5.5 \times 5$ & 1 & 2 & 2224.00 & 222.72 & 756896 & Top sheet crack $\sim 0.5 \mathrm{~mm}$ above rivet head \\
\hline 20. & $5.5 \times 5$ & 1 & 2 & 2090.88 & 209.28 & 1402372 & Bottom sheet crack a $4-8$ o'clock rivet head positions \\
\hline 21. & $5.5 \times 5$ & 1 & 2 & 2090.88 & 209.28 & 4839553 & Bottom sheet crack a $4-8$ o'clock rivet head positions \\
\hline
\end{tabular}

Table 3 Single-rivet SPR lap joint fabrication parameters and measured fatigue response with $3 \mathrm{~mm}$ thick aluminum alloy $5754-\mathrm{O}$ sheets

\begin{tabular}{|c|c|c|c|c|c|c|c|}
\hline S.No. & $\begin{array}{l}\text { Rivet } \\
\text { size }(\mathrm{mm})\end{array}$ & $\begin{array}{l}\text { Rivet head } \\
\text { set-down (mm) }\end{array}$ & Die & $P_{\max }(\mathrm{N})$ & $P_{\min }(\mathrm{N})$ & $N_{\mathrm{f}}$ (cycles) & Primary failure features \\
\hline 22. & $8 \times 5$ & 0.04 & 3 & 4893.12 & 489.60 & 124981 & Top sheet crack at $11-1$ o'clock position + rivet pull-out \\
\hline 23. & $8 \times 5$ & 0.04 & 3 & 4893.12 & 489.60 & 125514 & Top sheet crack at $11-1$ o'clock position + rivet pull-out \\
\hline 24. & $8 \times 5$ & 0.04 & 3 & 4893.12 & 489.60 & 126867 & Top sheet crack at $11-1$ o'clock position + rivet pull-out \\
\hline 25 & $8 \times 5$ & 0.04 & 3 & 5337.60 & 533.76 & 95308 & Top sheet crack at $10-1$ o'clock position \\
\hline 26. & $8 \times 5$ & 0.04 & 3 & 2668.80 & 266.88 & 3391114 & Bottom sheet crack at $8-4$ o'clock position \\
\hline 27. & $8 \times 5$ & 0.04 & 3 & 2668.80 & 266.88 & 3477589 & $\begin{array}{l}\text { Bottom sheet crack at } 8-4 \text { o'clock position }+ \\
\text { small top sheet crack at } 10-2 \text { o'clock position }\end{array}$ \\
\hline
\end{tabular}

servo-hydraulic fatigue testing machine. The joint dimensions were selected in order to avoid the influence of specimen size on failure mode and joint strength. ${ }^{4}$ In particular, the dimensions were chosen so as to prevent failure of the base sheet metal far away from the rivet.

\section{D finite-element analyses of SPR joints}

Using images of sectioned SPR specimens, 3D finiteelement models of the single-rivet joints were developed to obtain insights into the local mechanical behaviour under cyclic loading conditions. Three separate models were developed for each stack-up combination considered in the experimental program. Table 4 lists the three joints that were modelled and analysed: (1) denoted as 1-1, the sheets are each $1 \mathrm{~mm}$ thick, (2) denoted as $2-2$, the sheets are each $2 \mathrm{~mm}$ thick and (3) denoted as 3-3, the sheets are each $3 \mathrm{~mm}$ thick. Each model consists of two partially overlapping sheets joined by a rivet, as shown in Fig. 4a. The shape (geometry) of the rivets and surrounding sheet 

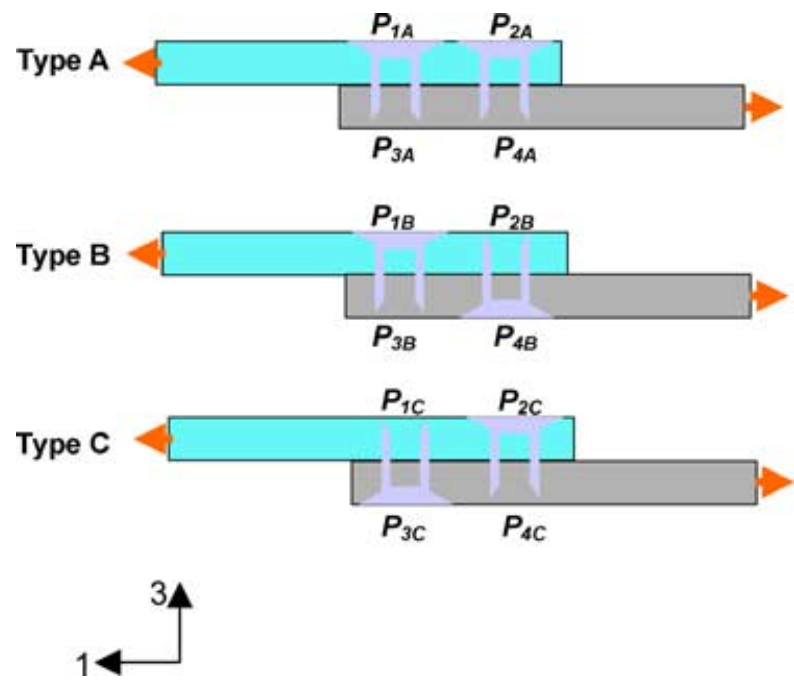

Fig. 3 Three riveting orientation combinations possible with double-rivet joints when the upper and lower sheet are identical. Types $\mathrm{B}$ and $\mathrm{C}$ can be distinguished by the section of the rivet that is nearest the loading end, i.e., the rivet heads $P_{1 B}$ and $P_{4 B}$ for Type $\mathrm{B}$ and rivet lower sections $P_{1 C}$ and $P_{4 C}$ for Type C. If the sheets are not identical, a fourth configuration, with both rivets inserted from the bottom, is also possible.

Table 4 Nomenclature for the finite-element models and the corresponding riveting process parameters

\begin{tabular}{ll}
\hline Model & Sheet thickness (mm) \\
\hline $1-1$ & 1 \\
$2-2$ & 2 \\
$3-3$ & 3 \\
\hline
\end{tabular}

material was obtained from magnified images of actual sectioned joints, shown in Fig. 4b. During the riveting process, an approximately cylindrical section of material that initially belongs to the upper sheet is punched out; this piece of material is also modelled as a fourth solid and is referred to as the 'dead metal' from hereon. It may be noted that the rivet head in case 3-3 was not flush with the upper sheet surface and a relatively large gap was present between the inner surface of the rivet head and dead metal. Each model represents one half unit of a single-rivet lap joint.

For the analyses, a nominal, remote loading cycle defined by $\sigma_{\max }=55.6 \mathrm{MPa}$ and $R=0.1$ was applied at the non-lapping end face of the upper sheet, while the corresponding face belonging to the lower sheet is fixed along the 1-axis. The corresponding value of maximum load for the three models are $P_{\max }=1779.2 \mathrm{~N}$ (1-1 case), $P_{\max }=3558.4 \mathrm{~N}$ (2-2 case) and $P_{\max }=5337.6 \mathrm{~N}$ (3-3 case). The tensile loading introduces a small bending moment that attains its maximum value when the applied stress reaches its maximum value during the load cycle, $\sigma_{\max }=$ 55.6 MPa. The maximum value of the bending moment is $2.5 \mathrm{Nm}, 5.0 \mathrm{Nm}$ and $7.5 \mathrm{Nm}$ in cases 1-1, 2-2 and 3-3, respectively. The loading edges of each sheet at a depth equal to the thickness of a single sheet were constrained in the $z$-direction to simulate the effect of the grips used in the cyclic tension tests. Calculations were performed for elastic aluminum alloy sheets and elastic steel rivets with the following properties: $E_{\mathrm{Al}}=70 \mathrm{GPa}, v_{\mathrm{Al}}=0.31$, $E_{\text {steel }}=206 \mathrm{GPa}, v_{\text {steel }}=0.33$. The coefficient of friction, $\mu=0.2$, was assumed across all interfaces.

The excess compliance of the model joint is defined as $C=C^{\prime}-C^{\prime \prime}$. Here, $C^{\prime}$, the joint compliance, is the ratio of the net extension, $\delta$, to the load per repeat distance, $P$, i.e. $C^{\prime}=\delta / P C^{\prime \prime}=92.06 \mathrm{~m} \mathrm{GN}^{-1}$ for case $1-1$ $\left(C^{\prime \prime}\right.$ is $46.03 \mathrm{~m} \mathrm{GN}^{-1}$ and $30.69 \mathrm{~m} \mathrm{GN}^{-1}$ for cases $2-2$ and $3-3$, respectively) is the compliance of a continuous panel having the same length, $L$, as the model joint (length of two panels minus the overlap) and the same cross-sectional area, $A$, and elastic modulus, $E$, as a single sheet. As the load is applied and the rivet tilts, the panels displace, bend and deform around the rivet. The excess compliance is related to these factors.

Three-dimensional FEA of SPR joints was performed using the ABAQUS/Standard finite-element program. Twenty-seven-noded brick and 15-noded prismatic elements were used to mesh the three bodies; single-noded slide surface elements were defined internally to solve the contact inequality constraints. The finite-element meshes typically consisted of about 17000 nodes, 3000 elements of which about 1650 were internally generated contact elements and approximately 47000 variables.

Estimating stresses and microslips in an SPR lap joint is not possible through closed-form analyses, and a numerical procedure such as FEA provides the only reasonable approach. Even with this approach, obtaining convergent solutions posed significant challenges, owing to numerous nonlinearities arising from 3D contact of four bodies (two sheets, rivet and dead metal), aspect ratios (thinness) of the compliant sheets and the geometries of the sheets in the riveted region. The meshes used for this study were developed according to guidelines derived from a previous, adequately validated analysis of airframe riveted lap joints. ${ }^{3}$ The present models do not account for the residual stresses produced in the joint because of the piercing operation.

\section{RESULTS}

\section{Fatigue behaviour of single-rivet joints}

Figure 5a shows the fatigue life data measured for the 27 single-rivet aluminum alloy 5754-O SPR joints as a function of the maximum load during the cycle. Figure $5 \mathrm{~b}$ 


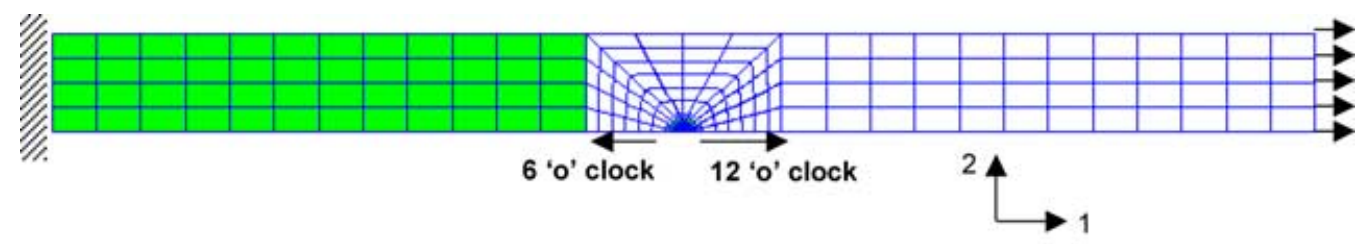

(a)

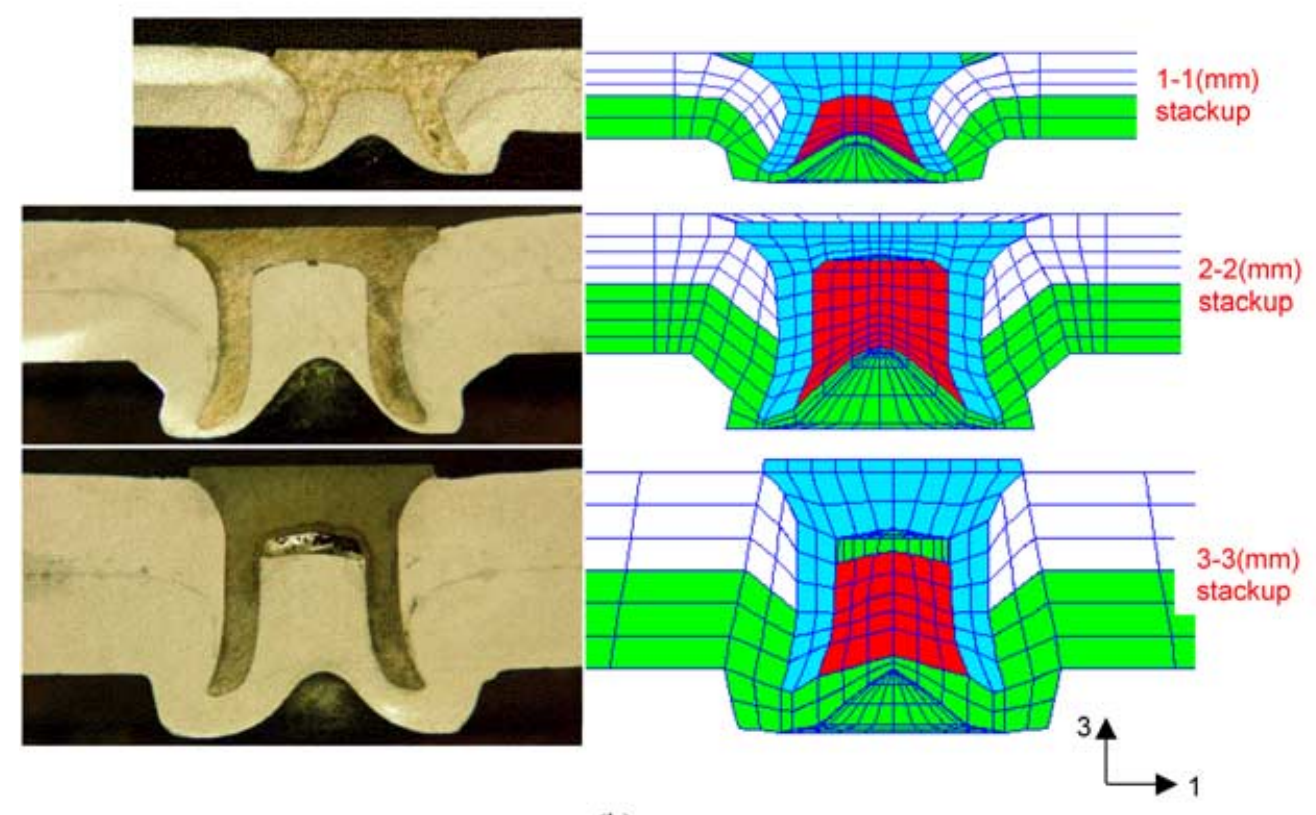

(b)

Fig. 4 (a) Plan view of a half-symmetry 3D finite-element model of a single-rivet SPR lap joint. (b) Three models were developed, one each for the three stack-up-combinations considered. The models were derived from images of actual sectioned joints.

shows the same data, but as a function of the maximum stress, $\sigma_{\max }$, during the load cycle. Near the lower end of the maximum stress examined $\left(\sigma_{\max } \approx 30 \mathrm{MPa}\right)$, a change in performance with sheet thickness (and related piercing process parameters) is not observed. However, for $\sigma_{\max } \approx$ $55 \mathrm{MPa}$, differences in the performance of the three joint types are evident. Near this value of applied stress, $N_{\mathrm{f}}$ is $\sim 21000,92000$ and 83000 cycles for the 1-1, 2-2 and 3-3 cases, respectively, as indicated in Fig. 5b. Surprisingly, the joint with 2 -mm-thick sheets shows a longer fatigue life than is shown by the one with 3 -mm-thick sheets. This is attributed to a sub-optimal riveting procedure with the 3-mm-thick sheets and considered further alongside the results from the FEAs in the next section.

Failure modes under repeated loading of the single-rivet joints are shown in Fig. 6. Three modes were observed: (i) gross section cracking of the upper sheet above the rivet head (mode 1) $(85 \%)$, (ii) rivet pull-out from the lower sheet (mode 2) (37\%) and (iii) net section cracking of the lower sheet (mode 3) (15\%). The most common mode of joint failure (23 out of 27 cases) was due to fatigue crack initiation ahead of the rivet head (near 12 'o' clock), i.e., in the sheet gross section, and on the faying (bottom) surface of the upper sheet (location $A$ in Fig. 7). This was usually accompanied by severe, permanent and localized bending of the sheet near the initiation location. The crack initiation location for this mode was typically $1-2 \mathrm{~mm}$ ahead of the rivet head. In about half of these cases, complete rivet disengagement from the lower sheet was also observed. In a small number (4) of cases, joint failure occurred due to fatigue crack initiation in the net section of the lower sheet hole near the 4 'o' clock and 8 'o' clock positions. This was observed only in the 2-2 and 3-3 stack-up cases and only when the stress range was very low $(\Delta \sigma<30 \mathrm{MPa})$. In general, more than one mode of failure was possible.

In addition to fatigue cracks, oxidized (black) wear debris due to fretting was also observed in all cases. The amounts of fretting damage due to rubbing between the rivet shank and the hole in the upper sheet and between the faying surfaces of the sheets were generally different. Direct visual observations revealed obvious differences in the severity of fretting damage and plastic bending deformation in the sheets with varying sheet stack-up. The amount of fretting damage was observed to increase with increasing sheet thickness, and the amount 


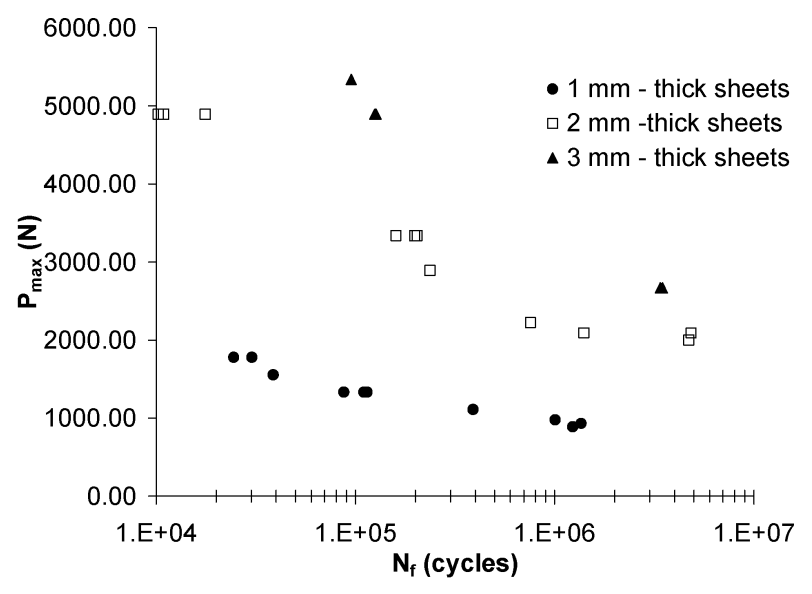

(a)

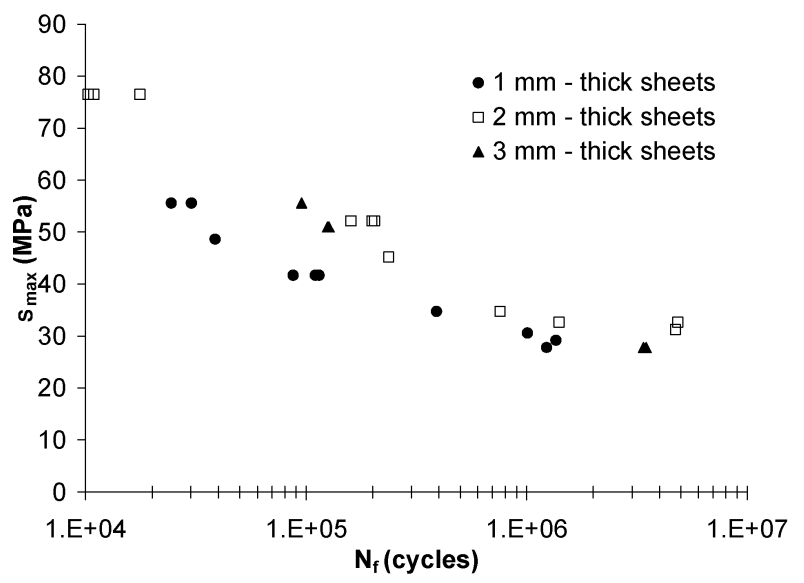

(b)

Fig. 5 Fatigue life measurements for the single-rivet aluminum alloy 5754-O SPR joints as a function of (a) the maximum load in the cycle, $P_{\max }$, and (b) the maximum stress in the cycle, $\sigma_{\max }$.

of permanent bending was found to decrease with increasing sheet thickness.

\section{Influence of orientation combination on strength of double-rivet joints}

Figure 8 shows a strong influence of the orientation combination of the two rivets in double-rivet aluminum alloy 5754-O SPR joints on fatigue life. Joint type B, in which the applied load encounters the rivet heads first, is found to exhibit the longest life. Joint type $\mathrm{C}$, in which the applied load encounters the flared lower sections of the rivets first, is found to have the shortest life. The average fatigue life of joint type $\mathrm{B}$ is about 2.2 times that of joint type $\mathrm{C}$ and 1.4 times the life of joint type A.

Figure 9 shows the influence of the orientation combination on joint ultimate tensile load. Once again, the performance of joint type $B$ is found to be superior to those of types $\mathrm{A}$ and $\mathrm{C}$, which are comparable. The ultimate tensile load with joint type B is about $7.5 \%$ higher. (a)

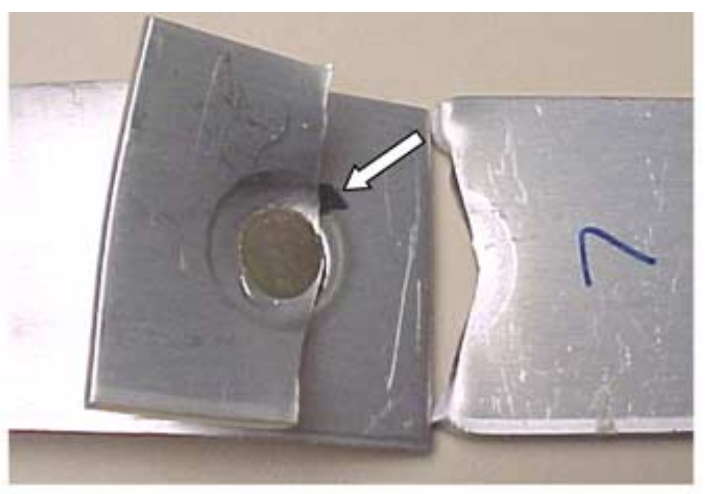

(b)

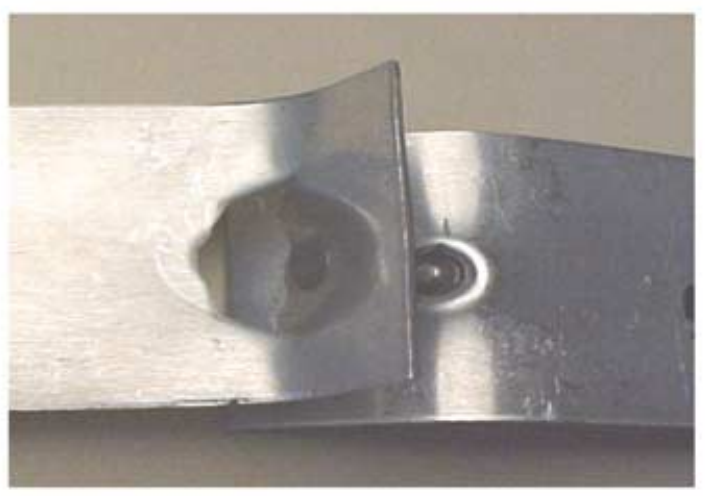

(c)

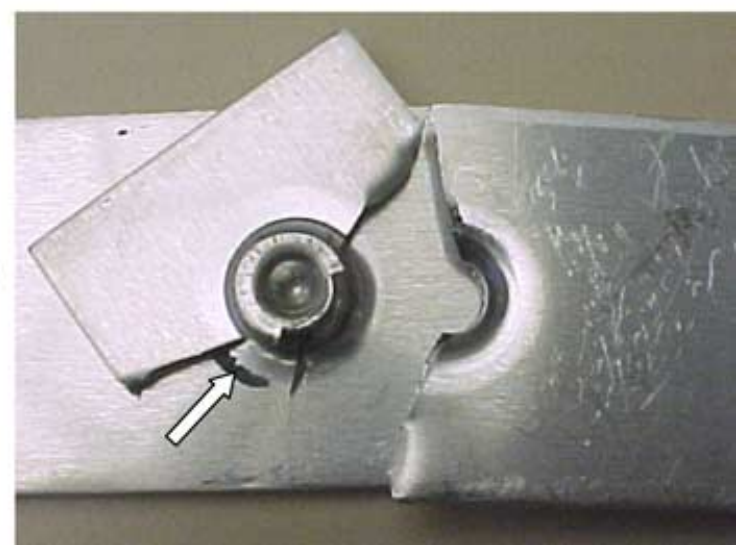

Fig. 6 Failure modes observed in the fatigue tested specimens: (a) mode 1 (rivet diameter $=5 \mathrm{~mm}$ ), (b) modes 1 and 2 (rivet diameter $=3 \mathrm{~mm}$ ), and (c) mode 3 (rivet diameter $=5 \mathrm{~mm}$ ). The black oxide debris in cases (a) and (c) is evidence of fretting.

\section{D finite-element analyses of single-rivet joints}

Deformed meshes for models 1-1, 2-2 and 3-3 under an applied stress of $\sigma_{\max }=55.6 \mathrm{MPa}$ are illustrated in Fig. 10. The shear load transferred by the sheets results in tilting of the rivet. The reaction to the moment, which is applied to the rivet heads, causes the sheets to bend. Sheet bending is accompanied by stress and strain gradients in the thickness direction, and both the bending and the tilting allow out-of-plane load transmission. Table 5, which refers to Fig. 11, lists the excess compliance of the joints 


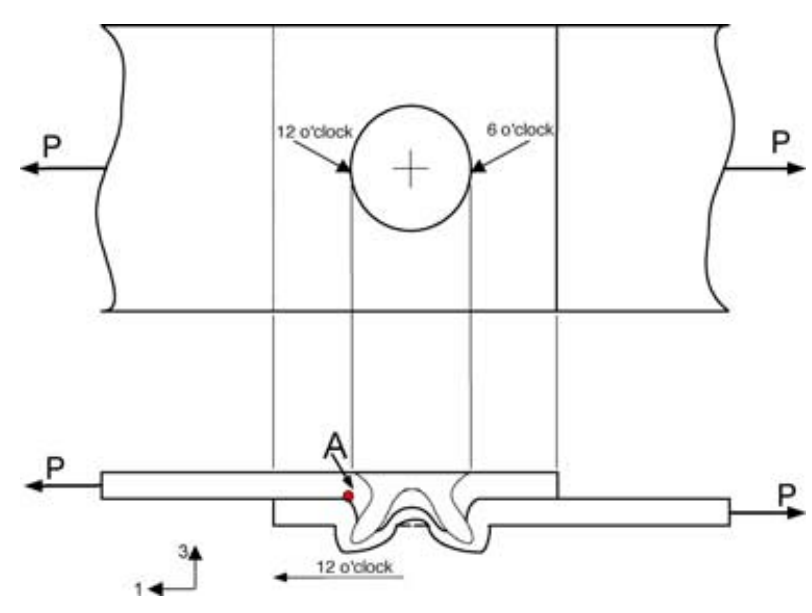

Fig. 7 Schematic showing the most commonly observed location, $A$, of fatigue crack initiation and failure in the SPR joints.

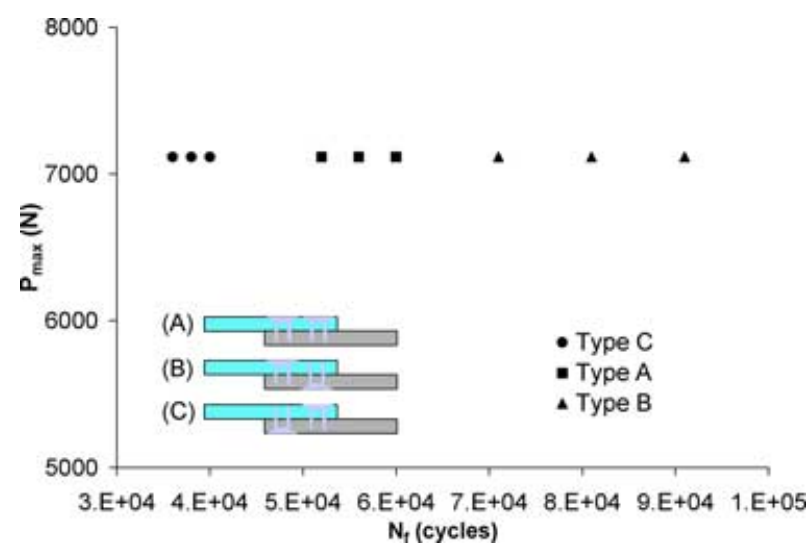

Fig. 8 Fatigue life measurements for the double-rivet aluminum alloy 5754-O SPR joints as a function of riveting orientation combination. The maximum load in the cycle is $P_{\max }$.

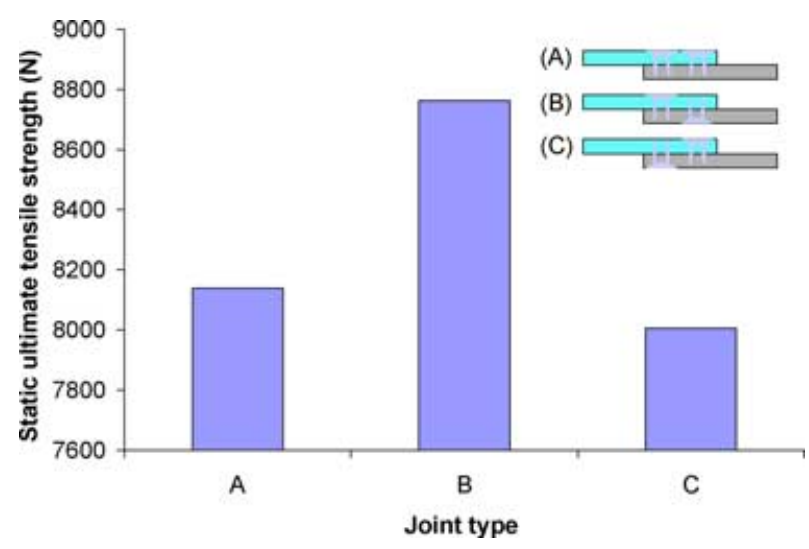

Fig. 9 Static ultimate tensile load measurements for the double-rivet aluminum alloy 5754-O SPR joints as a function of riveting orientation combination. and stress, contact pressure and microslip at various locations in the models. The mechanistic parameters shown relate to fatigue and fretting at the locations observed in the laboratory tested specimens.

Table 5 indicates that the joint excess compliance and peak stresses are related to each other and increase with in-plane microslip. Rivet tilt and out-of-plane microslip and bending are most evident with the 3-mm-thick sheets (Fig. 10), corroborated by the largest values of joint excess compliance, and in- and out-of-plane cyclic microslip values (Table 5). Referring to Fig. 11, tensile stress concentrations appear at locations $B$ and $C$ in the upper sheet and locations $A^{\prime}$ and $B^{\prime}$ in the lower sheet under the applied load. In the upper sheet, the largest computed tensile stress concentration is found to be in the gross section (at $C$ ) and is 13.7, 12.2 and 16.7 for models 1-1, 2-2 and $3-3$, respectively. In the lower sheet, the largest tensile stress concentration is found to be in the gross section (at $A^{\prime}$ ) in models $1-1$ and 2-2 and is 7.8 and 10.4 , respectively. In model 3-3, the largest tensile stress concentration is in the net section (at $B^{\prime}$ ) and has a value of 8.0. Consistent with the variation in fatigue life of the single-rivet joints with sheet thickness for $\sigma_{\max }=55.6 \mathrm{MPa}$ (Fig. 5b), the FEA results also indicate an anomalistic behaviour of the single-rivet joints with the 3 -mm-thick sheets.

As a result of the piercing process, the hole in the upper panel has a countersunk shape which results in a geometric nonlinearity near location $C$, at its interior surface. This feature along with sheet bending results in stresses that are higher at the interior sheet surfaces than at the exterior surfaces. The primary stress at location $A$ is compressive, owing to contact between the rivet shank and sheet hole (bearing), whereas it is tensile at $B$ and $C$, owing to sheet stretching and bending. Location $C$ is in the region where the majority of the fatigue cracks were observed in the laboratory experiments. In the lower sheet, the stresses at $C^{\prime}$ are compressive, owing to load bearing; the stresses at $A^{\prime}$ and $B^{\prime}$ are tensile, owing to sheet deformation.

The values of cyclic microslip and contact pressure listed in Table 5 are also related to fretting damage due to rivetupper sheet and upper-lower sheet contact. Out-of-plane contact between the sheets is responsible for the fretting damage observed in the regions around $A / A^{\prime}$ and $C / C^{\prime}$ and the peak contact pressures associated with this mechanism of joint wear.

\section{DISCUSSION}

To a first approximation, the fatigue life of the double-rivet SPR joint may be expected to be about twice that of an otherwise identical single-rivet joint. The average fatigue life of the 2-mm-thick double-rivet SPR joint for $P_{\max }=$ $7117 \mathrm{~N}\left(\sigma_{\max }=111.2 \mathrm{MPa}\right)$ is 81000 cycles (type B), 56000 cycles (type A), or 38000 cycles (type C), 


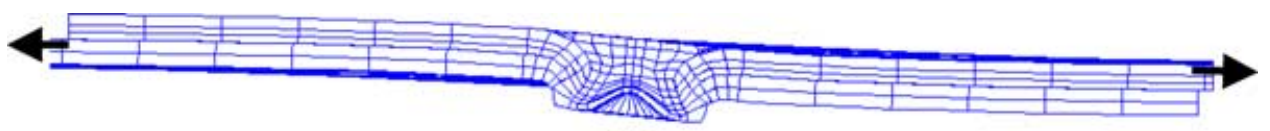

(a)

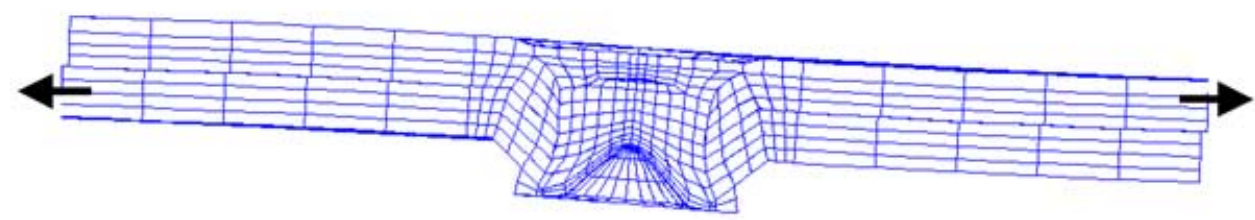

(b)

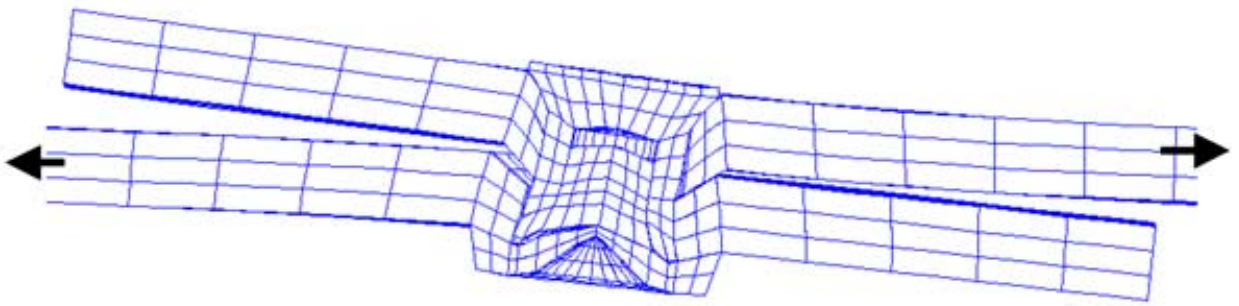

(c)

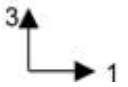

Fig. 10 Deformed finite-element meshes under a tensile load of $2502 \mathrm{~N}$ obtained with the three stack-up combinations. (a) 1-1 case, (b) 2-2 case and (c) 3-3 case.

Table 5 Computed mechanistic parameters that relate to the fatigue and fretting of the single-rivet elastic aluminium alloy SPR joints

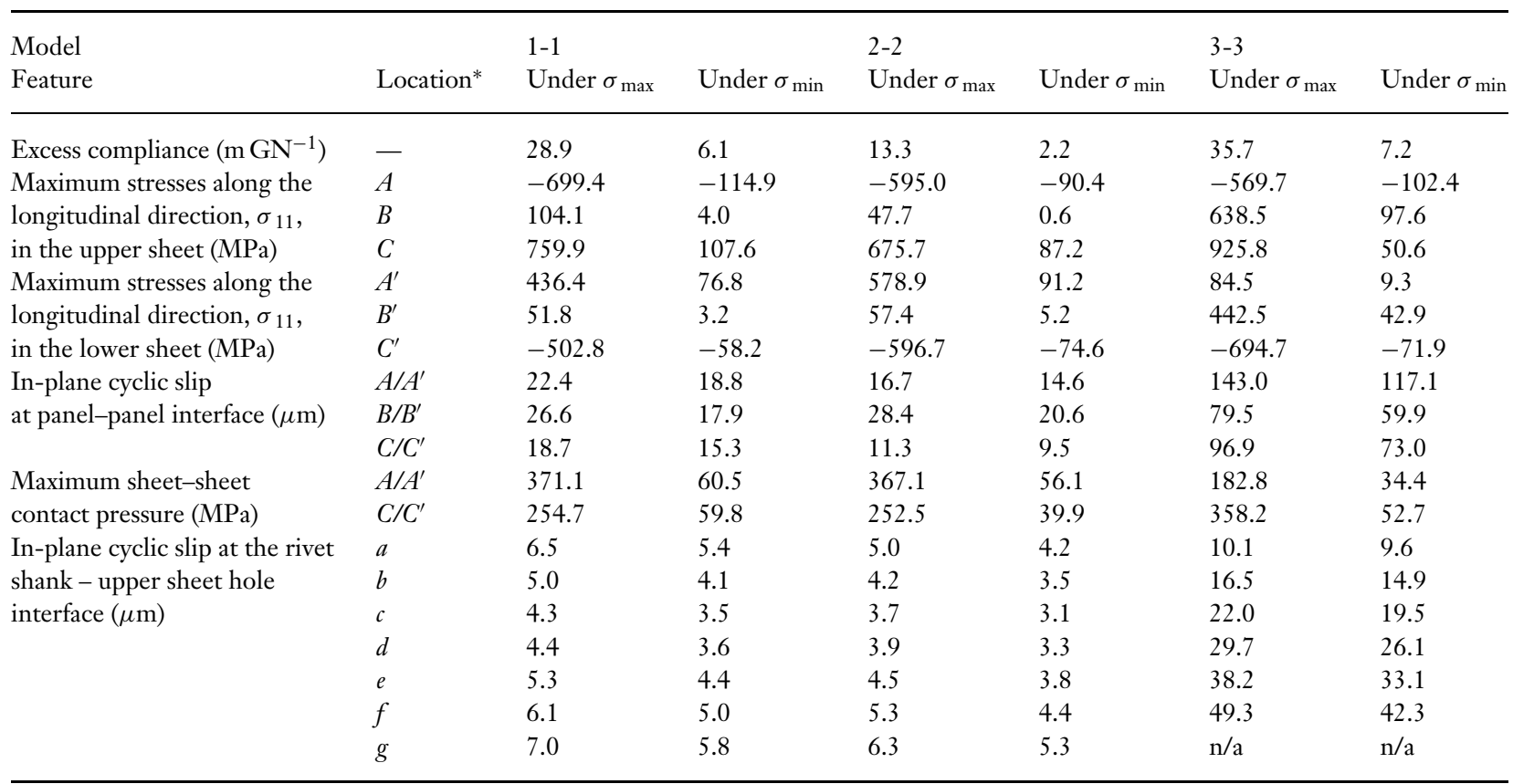

*shown in Fig. 11

depending on riveting orientation combination (see Fig. 8). Interpolation of the data shown in Fig. 5b indicates a fatigue life of 92000 cycles for the 2-mm-thick single-rivet joint at half the nominal maximum load, $P_{\max }$ $=3558.5 \mathrm{~N}\left(\sigma_{\max }=55.6 \mathrm{MPa}\right)$. The comparison shows that the fatigue life of the type B double-rivet SPR joint is somewhat less than that of a similar single-rivet SPR joint, for the same value of applied stress per rivet $(3558.5 \mathrm{~N})$. With the sub-optimal double-rivet joints, the loss in fatigue performance is even greater for this value of applied 


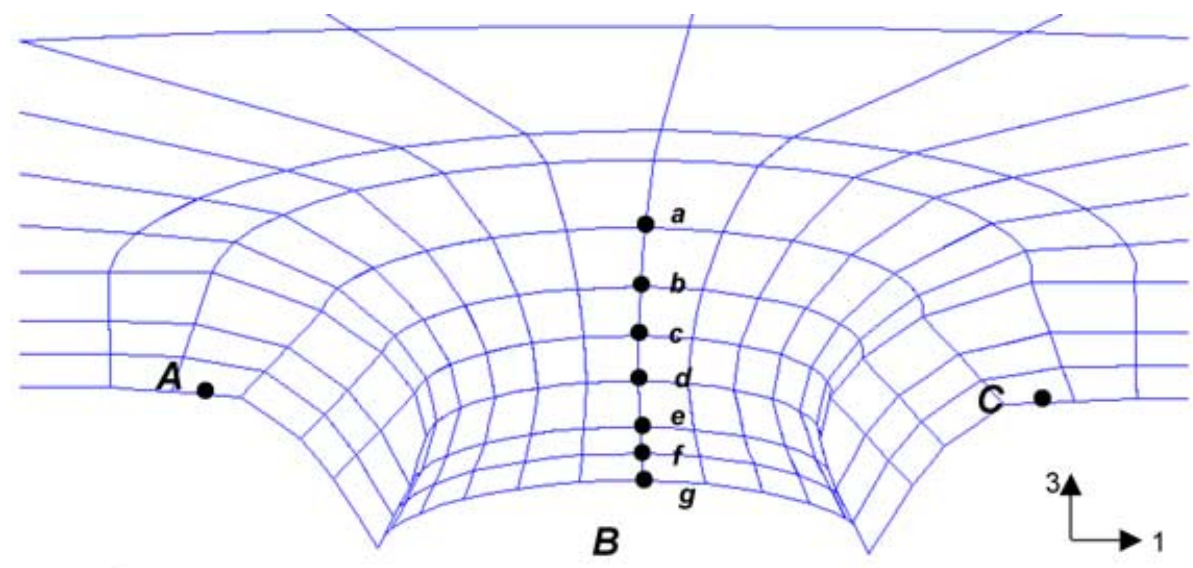

(a)

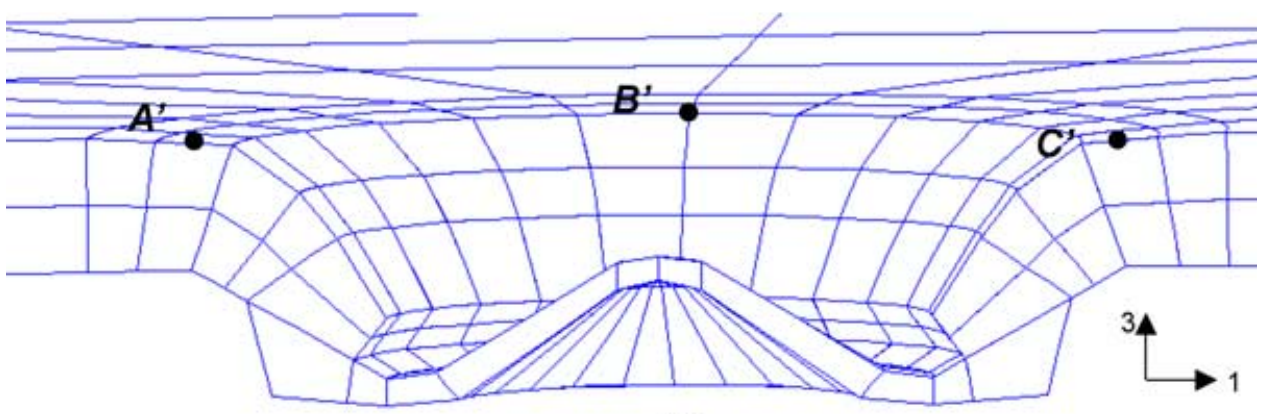

(b)

Fig. 11 Definition of locations at which mechanistic parameters listed in Table 5 were obtained.

stress per rivet-the fatigue life of the type A and type C double-rivet SPR joints are only approximately onethird and one-fourth that of the comparable single-rivet joint.

While a less than proportionate reduction in leading row stress concentration factor with increasing numbers of fastener rows is known ${ }^{5}$ and related to non-equal load bearing between adjacent fastener rows in other types of multi-fastener-row structural shear joints, ${ }^{6}$ the present fatigue life measurements indicate no additional benefit from a second row of fasteners in SPR joints. The limited amount of data obtained in this study and current understanding of the micromechanics of SPR joints preclude substantive speculation as to the cause or generality of this finding vis-a-vis multiple-rivet-row SPR joints. It is possible that the observed loss in performance with the double-rivet joints may not be as notable with a different spacing between adjacent rivets (pitch), sheet dimensions, applied load magnitude, multiaxial loading, etc. The influence of SPR structural joint design parameters on fatigue performance presents an important area for systematic study.

A finding that is relevant to the design of SPR joints is that the majority of the joints failed in the gross section of the upper sheet, i.e., the initiation of the primary crack was in the faying surface of the upper sheet above the rivet head (12 O'clock). Net section failures were found to occur, but only when the sheet thickness was $2 \mathrm{~mm}$ or $3 \mathrm{~mm}$ and under high-cycle fatigue conditions $\left(N_{\mathrm{f}}>\right.$ 1 million cycles). Recent studies of riveted joints show that the highest tensile stress concentrations in the upper sheet hole is always near the faying surface, but its exact location depends on the amount of fastener clamping and level of applied load; depending on these, the site of maximum stress concentration can shift from the net section to the gross section. ${ }^{7}$ In an effort to explain the change in the failure mode from fatigue cracking at the 12 ' $\mathrm{o}$ ' clock location in the upper sheet (location $C$ ) to the $8 / 4$ ' 0 ' clock location in the lower sheet (location $B^{\prime}$ ) at small values of applied stress, the maximum tensile stress values at those locations for a nominal, applied stress, $\sigma_{\max }=30 \mathrm{MPa}$ were determined as shown as follows (in $\mathrm{MPa}$ ):

\begin{tabular}{llll}
\hline & \multicolumn{3}{c}{ Maximum tensile stress values (in MPa) } \\
& Model 1-1 & Model 2-2 & Model 3-3 \\
\hline Location $C$ & 432.7 & 371.7 & 477.6 \\
Location $B^{\prime}$ & 56.9 & 50.7 & 239.2 \\
\hline
\end{tabular}


The disparity in computed values of maximum stress at the two locations does decrease for the lower value of applied stress and with increasing sheet thickness-both of these observations are consistent with the experimental results. However, the maximum stress at $B^{\prime}$ is always significantly smaller than that at $C$ and therefore cannot in itself explain the shift in the failure location observed in the experiments.

The FEA results in Table 5 can also be used to examine the expected severity of fretting wear through the parameter $F_{1}=\mu p \delta,{ }^{8}$ which is a measure of the energy expended in frictional microslip; $\mu$ is the coefficient of friction, $p$ is the contact pressure and $\delta$ is the microslip amplitude (amount of relative movement between the contacting surfaces). The maximum computed values of $F_{1}$ for fretting at the faying surface in cases 1-1, 2-2 and 3-3 were found to be as follows:

\begin{tabular}{rl}
\hline Faying surface & $F_{1}(\mathrm{kPa} \mathrm{m})$ \\
\hline $1-1$ & 0.95 \\
$2-2$ & 0.57 \\
$3-3$ & 6.9 \\
\hline
\end{tabular}

These estimates indicate a large amount of fretting wear in case 3-3 and much smaller amounts in cases 1-1 and $2-2$. This is generally consistent with qualitative visual estimates of fretting damage observed in the three cases.

Both the experimental results and FEA reflect a trend reversal in fatigue performance parameters with the singlerivet SPR joints that use the 3-mm-thick 5754-O alloy sheets at $\sigma_{\max } \approx 55 \mathrm{MPa}$. The measured fatigue life with the 3 -mm-thick sheets is found to be intermediate between the measurements with the 1- and 2-mm-thick sheets. And, contrary to the trend of decreasing joint excess compliance, stresses and slips as the sheet thickness is increased from 1 to $2 \mathrm{~mm}$, the joint with the $3-\mathrm{mm}$ thick sheets exhibits the greatest compliance and largest values of stress and cyclic microslip. The behaviour with the 3-mm-thick sheets is believed to be anomalistic and related to the joint quality, which may have been sacrificed to some degree by the non-flush rivet head. The non-flush rivet head and void between the rivet head and dead metal suggest a marginally incomplete riveting procedure and an inadequate rivet head set down.

The broad agreements between the experiments and analyses emphasize a correlation between the cold-formed geometry and macroscopic frictional locking mechanisms of the SPR joint and fatigue life. However, differences are significant as well. The analyses predict the shortest life for the joints with the 3 -mm-thick sheets (compare stress concentrations at location $C$ in Table 5), which was not observed experimentally. The occurrence of gross section failure in most of the SPR joints tested is indicative of high levels of clamping residual stresses, which are not included in the finite-element modelling. The calculations demonstrate that the geometric nonlinearities determine the locations of fatigue crack initiation but that post-piercing residual stresses cannot be neglected for predicting fatigue life.

\section{CONCLUSIONS}

1 In the low-cycle fatigue regime and up to the high-cycle regime $\left(N_{\mathrm{f}}<10^{6}\right.$ cycles), gross section failures are observed in SPR joints. Fatigue crack initiation is found to occur on the faying surface of the upper sheet.

$23 \mathrm{D}$ elastic FEA shows that the maximum tensile stress concentration in a loaded SPR is located in the region exhibiting gross section crack initiation. This finding highlights the importance of the cold-formed geometric nonlinearities in determining joint mechanical strength.

3 Net section fatigue failure, with crack initiation on the faying surface of the lower sheet, is also possible in SPR joints. This mode of failure is observed only in the highcycle fatigue regime, i.e., $N_{\mathrm{f}}>10^{6}$ cycles, and for thicker sheets.

4 Both the fatigue and static strength of double-rivet SPR joints are found to be strongly dependent on the orientation combination of the rivets. The combination for which the rivet heads are closest to the loading ends is found to exhibit the greatest strength.

5 The fatigue life of the double-rivet SPR joints is found to be no better than one half of that of a similar single-rivet joint, for the same value of applied stress per rivet.

6 The severity of fretting damage in SPR joints is observed to increase with sheet thickness.

\section{Acknowledgements}

This research was supported by the General Motors Collaborative Research Lab (GMCRL) at the University of Michigan. The authors are grateful to Mr. Bill King and Mr. Randall Leedy and Emhart Fastening Teknologies for providing the SPR apparatus, dies and rivets used in the study. The authors also acknowledge Dr. Robert Cacko for assistance with the finite-element model development.

\section{REFERENCES}

1 Krause, A. R. and Chernenkoff, R. A. (1995) A comparative study of the fatigue behavior of spot welded and mechanically fastened aluminum joints. SAE Paper No. 950710.

2 Booth, G. S., Olivier, C. A., Westgate, S. A., Liebrecht, F. and Braunling, S. (2000) Self-piercing riveted joints and resistance spot welded joints in steel and aluminum. SAE Paper No. 2000-01-2681. 
3 Iyer, K., Rubin, C. A. and Hahn, G. T. (2001) Influence of interference and clamping on fretting fatigue in aluminum, single rivet-row lap joints. F. Tribol. 123, pp. 686-698.

4 Zhou, M. (2000) A Unified Approach to Assessing the Mechanical Performance of Resistance Spot Welds, $\mathrm{PhD}$ Thesis, The University of Michigan, Ann Arbor.

5 Iyer, K., Rubin, C. A. and Hahn, G. T. (2001)

Three-dimensional analyses of double rivet-row lap joints Part I: Non-countersunk rivets. In: Reliability, Stress Analysis and Failure Prevention, ASME DE - Vol. 114, pp. 19-31, The American Society of Mechanical Engineers, New York.
6 Kulak, G. L., Fisher, J. W. and Struik, H. A. J. (1987) Guide to Design Criteria for Bolted and Riveted Joints, American Institute of Steel Construction, Chicago.

7 Iyer, K., Hahn, G. T. and Rubin, C. A. (2004) Clamping and failure mode transitions in structural shear joints. In: Analysis of Bolted Foints, ASME PVP - Vol. 478, pp. 1-9, The American Society of Mechanical Engineers,

New York.

8 Ruiz, C. P., Boddington, H. B. and Chen, K. C. (1984) Investigation of fatigue and fretting in a dovetail Joint. Exper. Mech. 24, 208-217. 